\title{
Recombinant Interferon Alfa
}

National Cancer Institute

\section{Source}

National Cancer Institute. Recombinant Interferon Alfa. NCI Thesaurus. Code C225.

A class of naturally-isolated or recombinant therapeutic peptides used as antiviral and anti-tumor agents. Alpha interferons are cytokines produced by nucleated cells (predominantly natural killer (NK) leukocytes) upon exposure to live or inactivated virus, double-stranded RNA or bacterial products. These agents bind to specific cell-surface receptors, resulting in the transcription and translation of genes containing an interferonspecific response element. The proteins so produced mediate many complex effects, including antiviral effects (viral protein synthesis); antiproliferative effects (cellular growth inhibition and alteration of cellular differentiation); anticancer effects (interference with oncogene expression); and immune-modulating effects (natural killer cell activation, alteration of cell surface antigen expression, and augmentation of lymphocyte and macrophage cytotoxicity). ( $\mathrm{NCl04)}$ 